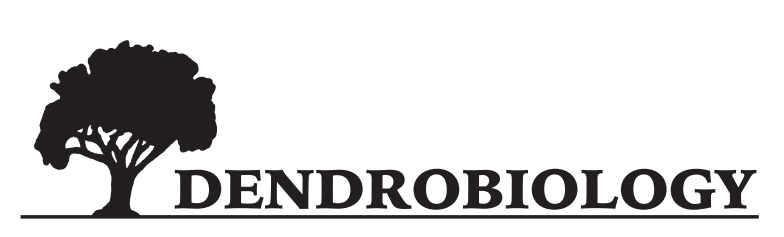

2015, vol. 73, 153-162

http://dx.doi.org/10.12657/denbio.073.016

\author{
Wiestaw Prus-Głowacki, Lidia Sukovata, Anetta Lewandowska-Wosik, \\ Romana Nowak-Bzowy
}

\title{
Shikimate dehydrogenase (E.C. 1.1.1.25 ShDH) alleles as potential markers for flowering phenology in Pinus sylvestris
}

Received: 2 June 2014; Accepted: 26 January 2015

\begin{abstract}
The aims of this study were 1) to determine the variability in the flowering phenology of Scots pine (Pinus sylvestris L.) clones in a seed orchard and 2) to compare the genetic structure and genetic markers (13 isozyme loci and 5 chloroplast and 3 nuclear DNA microsatellite loci) among groups of clones that are differentiated by flowering phenology. Using the timing of male inflorescence development, 57 plus trees represented by their clones in a seed orchard were classified into three phenological groups: early-, intermediate-, and late-flowering. The microsatellites showed no significant differences in the genetic structure of the analyzed phenological groups. However, the frequency of allele 2 at the shikimate dehydrogenase A locus (ShDH A 2) differed significantly between the groups of early- and late-flowering trees and between the groups of intermediate- and late-flowering trees. In addition, a significant difference in the frequencies of the genotype $\mathrm{ShDH}$ A 11 was observed between the intermediate- and late-flowering groups. Nei's genetic distance indicated that the late-flowering group was the most genetically distant among the phenological groups. These results suggest that the ShDH A locus might be considered as isoenzymatic marker that differentiates these flowering groups of Scots pine clones. At several isozyme and DNA loci, the presence of private alleles in each group of pines was observed. However, these alleles cannot serve as markers of Scots pine flowering time because of their low frequencies.
\end{abstract}

Additional key words: Scots pine, male inflorescence, isozymes, chloroplast DNA, nuclear DNA

Addresses: W. Prus-Głowacki, A. Lewandowska-Wosik, R. Nowak-Bzowy, Adam Mickiewicz University, Institute of Experimental Biology, Genetics Department, 89, Umultowska Str., 61-614 Poznań, Poland, e-mail: prusw@amu.edu.pl

L. Sukovata, Forest Research Institute, Forest Protection Department, 3, Braci Lesnej St., Sekocin Stary, 05-090 Raszyn, Poland

\section{Introduction}

Flowering phenology is fundamental for plant reproduction because it determines the mating system and fertilization success. In seed orchards, the genet- ic structure and genetic value of seeds depend on the clone composition, the synchronization of flowering time and individual fertility (Boes et al. 1991; Puglisi et al. 1999; Gömöry et al. 2003; Wasielewska et al. 2005; Neimane et al. 2009; Ivanek et al. 2013). 
Plant flowering phenology is a variable trait that has a high degree of heritability. The possible genetic background for the flowering phenology of the Scots pine is indicated by observations of variation in the flowering time among different clones in seed orchards (Sarvas 1962; Jonsson et al. 1976; Chung 1981a; Boes et al. 1991; Burczyk and Chalupka 1997; Neimane et al. 2009). However, few studies have focused on identifying an association between the genetic structure and phenological variation in Scots pine. Using six isozyme loci (three glutamate oxaloacetate transaminase [GOT], one glutamate dehydrogenase $[\mathrm{GDH}]$ and two leucine aminopeptidase [LAP] loci), Chung (1981b) found no differences in the allelic frequency between early- and late-flowering clones originating from provenances throughout Finland. Karhu et al. (1996) examined the variation patterns of several types of molecular markers [isozymes, RFLPs (restriction fragment length polymorphisms) of ribosomal DNA and of anonymous low-copy number DNA, RAPDs (random amplified polymorphic DNA) and microsatellites] and the timing of bud sets in one-year-old pine seedlings. The authors concluded that molecular markers are poor predictors of population differentiation of the bud set time. However, both studies analyzed clones that originated from different latitudes rather than samples from the same population.

In such a case, the isolation-by-distance or environmental variation my be a factors influenced of the observed genetic differetiation between clons precluding accurate inferens on the associations between molecular markers and the variation in the buds set time. In order to avoid these problems this study was performed in a seed orchard established in the same locality, based on plus trees selected within a single, large forest complex (the Notec forest) The aims of the study were: 1) to determine the variability in the flowering phenology of Scots pine clones and 2) to compare the genetic variation in clone groups that differed in their flowering phenology using molecular markers, i.e., isozyme loci and chloroplast and nuclear DNA microsatellite loci.

\section{Methods}

\section{Study area}

The investigations were performed in a seed orchard $\left(52^{\circ} 29^{\prime} \mathrm{N}, 16^{\circ} 15^{\prime} \mathrm{E}\right)$ established in 1993 in the Dąbrowa Forest District, Pniewy Forest Division, Regional Directorate of State Forests in Poznań, Poland. The shoots for grafting were sampled from 57 Scots pine plus trees that were selected from a large forest complex - the Notec forest $\left(52^{\circ} 42^{\prime} \mathrm{N}, 16^{\circ} 04^{\prime} \mathrm{E}\right)$.

Table 1. Isoenzymatic and DNA microsatellite loci

\begin{tabular}{|c|c|c|}
\hline Item & Locus & Abbreviation \\
\hline \multicolumn{3}{|c|}{ Isozyme } \\
\hline 1 & EC 1.1.1.44 phosphogluconate dehydrogenase & 6PGD \\
\hline 2 & EC 1.6.4.3 diaphorase & DIAF \\
\hline 3 & EC 3.1.1.2 fluorescent esterase & FEst \\
\hline 4 & EC 1.4.1.2 glutamate dehydrogenase & GDH \\
\hline 5 & EC 2.6.1.1 glutamic-oxalacetic transaminase locus A & GOT A \\
\hline 6 & glutamic-oxalacetic transaminase locus B & GOT B \\
\hline 7 & glutamic-oxalacetic transaminase locus $\mathrm{C}$ & GOT C \\
\hline 8 & EC 1.1.1.37 malate dehydrogenase locus A & $\mathrm{MDH} \mathrm{A}$ \\
\hline 9 & malate dehydrogenase locus $\mathrm{C}$ & $\mathrm{MDH} \mathrm{C}$ \\
\hline 10 & EC 1.6.99.3 NADH-dependent dehydrogenase & $\mathrm{NDH}$ \\
\hline 11 & EC 2.7.5.1 phosphoglucomutase & PGM \\
\hline 12 & EC 1.1.1.25 shikimate dehydrogenase locus A & ShDH A \\
\hline 13 & shikimate dehydrogenase locus B & ShDH B \\
\hline \multicolumn{3}{|c|}{ Chloroplast DNA } \\
\hline 14 & PCP 71987 & CP3 \\
\hline 15 & PCP 30277 & $\mathrm{CP} 4$ \\
\hline 16 & PCP 45071 & CP5 \\
\hline 17 & Pt 45002 & $\mathrm{CP} 6$ \\
\hline 18 & Pt 30204 & CP7 \\
\hline \multicolumn{3}{|c|}{ Nuclear DNA } \\
\hline 19 & PtTX 4001 & 4001 \\
\hline 20 & PtTX 4011 & 4011 \\
\hline 21 & SPAG 7.14 & 7.14 \\
\hline
\end{tabular}




\section{Assessment of variability in the flowering phenology of Scots pine plus trees}

The development of male inflorescence was assessed during the initial phase of tree flowering at the end of April 2008. Clones of all 57 plus trees were analyzed, each with two to five replications (clones). The level of inflorescence development was evaluated as the extent to which the inflorescence was covered by scales according to the following scale, which was developed by the authors of this study:

- inflorescence in closed scales,

- inflorescence in loose scales (microstrobili are visible),

- approximately one-fourth of an inflorescence surface without scales,

- approximately half of an inflorescence surface without scales,

- approximately three-quarters of an inflorescence surface without scales,

- entire inflorescence without scales.

The level of inflorescence development per clone was evaluated for 10 male inflorescences on different sides of the crown. Next, the average was calculated for each clone and then for each plus tree. Each plus tree was assigned to one of three phenological groups: 1) early-flowering, 2) intermediate-flowering, and 3) late-flowering.

\section{Molecular analyses}

Winter buds collected in November 2008 from the shoots in the lower part of the crown of one clone of each plus tree were used in the analyses of genetic variation in the phenological groups.

To determine the variation of isozymes, 13 polymorphic loci were selected (Table 1). Isozyme electrophoresis, which was used in the analyses and in the genetic interpretation of the results, was based on methods described by Muona and Szmidt (1985) and by Prus-Głowacki and Stephan (1994). Chloroplast and nuclear DNA variations were investigated using five and three microsatellite loci, respectively (Table 1).

Total DNA isolated from the winter buds was used to analyze chloroplast and nuclear DNA variations. The buds were stored at $-20^{\circ} \mathrm{C}$ until DNA isolation. Total genomic DNA was extracted from buds using CTAB method (Doyle and Doyle 1990). Quality and quantity of the isolated DNA were measured using a Nanodrop ${ }^{\mathrm{TM}}$ ND-1000 spectrophotometer and diluted to a final concentration of $20 \mathrm{ng} / \mathrm{ul}$. The amplified fragments were analyzed using an ABI Prism 3130xl Genetic Analyzer (Applied Biosystems ${ }^{\circledR}$, Life Technologies; Foster City, California USA) according to the methods described previously by Vendramin et al. (1996), Soranzo et al. (1998), Provan et al. (1999) and Auckland et al. (2002).

The following genetic parameters were calculated: frequencies of alleles $(A)$ and genotypes $(G)$; frequencies of chloroplast DNA haplotypes; mean number of alleles and genotypes per locus $(A / L$ and $G / L$, respectively); observed $\left(H_{\mathrm{O}}\right)$ and expected $\left(H_{\mathrm{E}}\right)$ heterozygosities; haploid genetic diversity $(h)$; Wright's inbreeding coefficient $(F)$ to determine excess or deficiency of heterozytotes as compare to Hardy-Weinberg equilibrium; genotypic polymorphism $\left(P_{\mathrm{g}}\right)$; genetic differentiation of the groups $\left(G_{\mathrm{ST}}\right)$; and Nei's genetic distance coefficient $\left(D_{\mathrm{N}}\right)$ based on allelic frequency (Nei 1972, 1978). In order to verify the hypothesis of neutrality of given loci we used the Ewens-Watterson test for neutrality (Hedrick 2011). The alleles and genotypes that occurred in only one of the three phenological groups of clones were classified as private.

The genetic parameters for the isozyme loci and for the microsatellite loci and the significance of the differences in the frequencies of the alleles and genotypes, which were examined using the $\chi^{2}$ test (at the Bonferroni adjusted $\alpha=0.01$ ), were calculated using POPGENE, version 1.31 (Yeh and Yang 1999), and GenAlEx, versions 6 and 6.5, (Peakall and Smouse 2006, 2012) software.

\section{Results}

\section{Phenological groups of the Scots pine plus trees}

The average level of inflorescence development ranged from 1.0-5.1 (Fig. 1). Based on the results of the flowering assessment, the plus trees were divided into the following three groups:

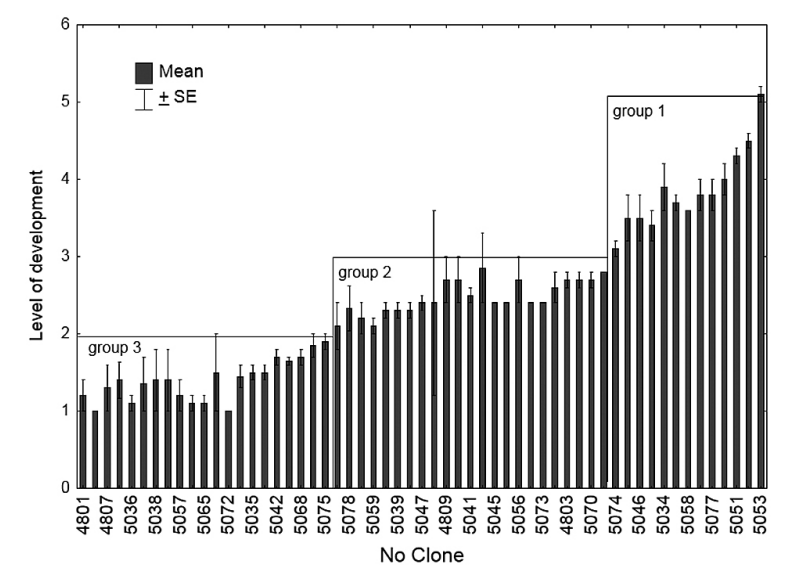

Fig. 1. Level of male inflorescence development in 57 Scots pine plus trees. The lines divide the trees into three phenological groups: 1 - early-flowering, 2 - intermediate-flowering, 3 - late-flowering 
- the early-flowering group, with an average level of inflorescence development $>3.0$ (range 3.1-5.1; 13 plus trees),

- the intermediate-flowering group, with an average level of inflorescence development $>2.0$ and $<3.0$ (range $2.1-2.8 ; 23$ plus trees)

- the late-flowering group, with an average level of inflorescence development $<2.0$ (range 1.0-1.9; 21 plus trees).

\section{Isozymes}

\section{Frequency of alleles}

All of the 13 examined loci were polymorphic in the three groups of trees. The analysis of allelic frequency showed that the highest number of alleles (four) was recorded for the fluorescent esterase
(FEst) and shikimate dehydrogenase (ShDH A) loci. The mean numbers of alleles per locus $(A / L)$ in the early-, intermediate- and late-flowering groups were $2.46,2.69$ and 2.61 , respectively, and the mean value for all of the loci was 2.58 .

A statistically significant difference in the allelic frequency was found for the ShDH A 2 allele between the early- and late-flowering groups $\left(\chi^{2}=\right.$ $7.19, \mathrm{P}<0.01)$ and between the intermediate- and late-flowering groups $\left(\chi^{2}=5.83, \mathrm{P}<0.01\right)$, with an increase in the frequency of this allele from the early- to late-flowering trees (Fig. 2). In contrast, a markedly lower allelic frequency was recorded for the ShDH A 1 allele in the late-flowering group than in the other two groups. In several cases, downward or upward trends were observed for frequencies in the individual alleles, e.g., a decrease in the frequency of

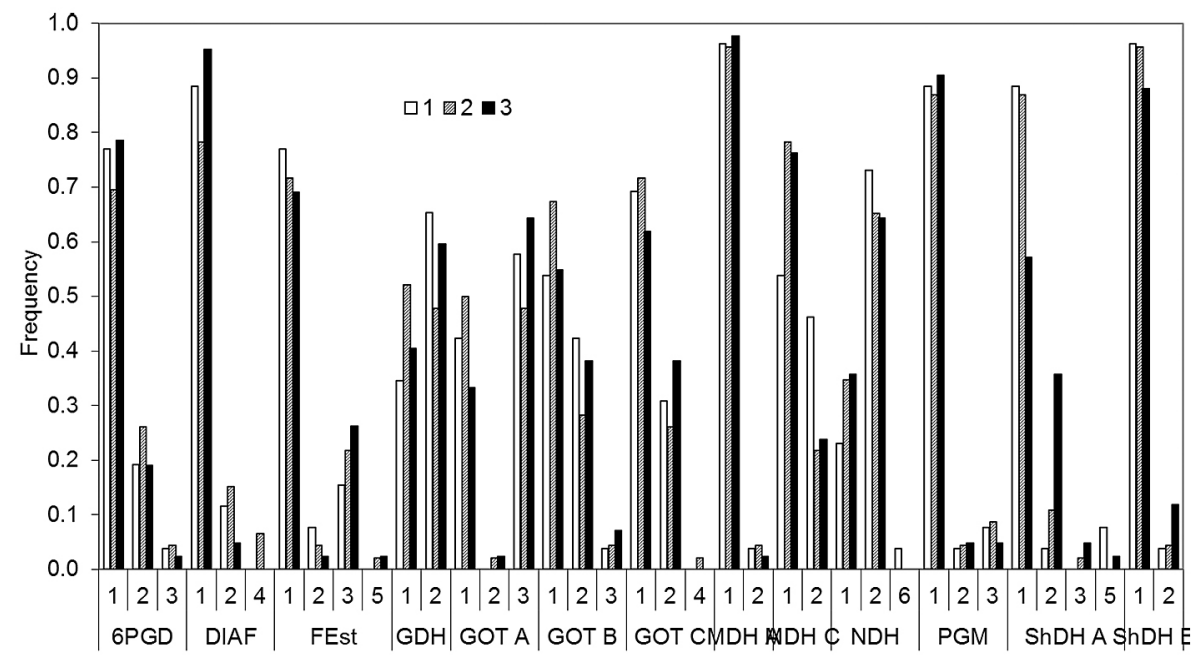

Loci and alleles

Fig. 2. Frequency of isoenzymatic alleles for 13 loci in three phenological groups of Scots pine plus trees ( 1 - early-flowering, 2 - intermediate-flowering, 3 - late-flowering)

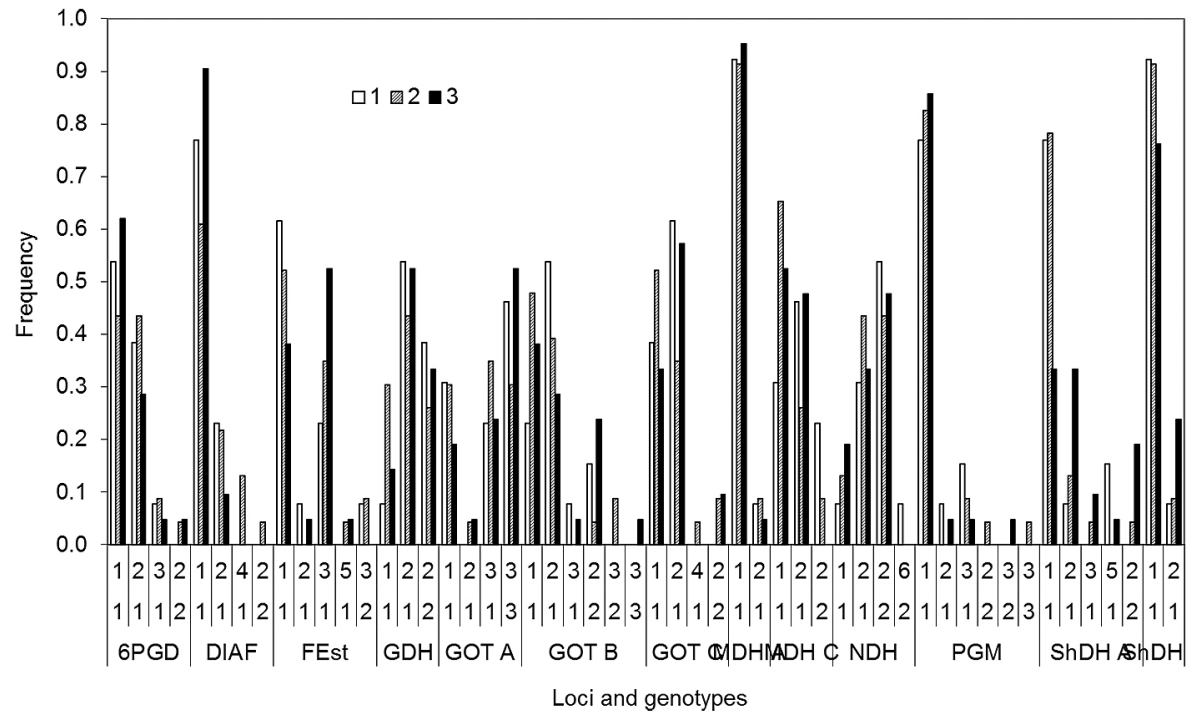

Fig. 3. Frequency and number of isoenzymatic genotypes for 13 loci in three phenological groups of Scots pine plus trees ( 1 - early-flowering, 2 - intermediate-flowering, 3 - late-flowering) 
alleles FEst 1, FEst 2 and ShDH B 1was observed from the early- to late-flowering trees, whereas the frequency increased for alleles FEst 3 and ShDH B 2.

One private allele (NDH 6, with a frequency of $3.8 \%)$ was detected in the early-flowering tree group (Fig. 2), whereas two private alleles (DIAF 4 and GOT C 4 , with frequencies of $6.5 \%$ and $2.2 \%$, respectively) were detected in the intermediate-flowering tree group. Private alleles were not detected in the late-flowering tree group.

\section{Number and frequency of genotypes}

The mean numbers of genotypes were higher in the intermediate- and late-flowering tree groups (3.46 and 3.31, respectively) than in the early-flowering tree group (2.92). The highest numbers of genotypes were found at two loci, GOT B and PGM. The numbers and frequencies of genotypes are presented in Fig. 3.

A statistically significant difference in the genotypic frequency was observed between the intermediate- and late-flowering trees for ShDH A $11\left(\chi^{2}=\right.$ $3.98, \mathrm{P}<0.01)$. The frequency of this homozygous genotype in the latter group was more than $50 \%$ lower than in the other groups, whereas the heterozygous genotype of ShDH A 12 was much more frequent. In addition, markedly decreasing trends from the early- to late-flowering trees were observed for the genotypic frequencies of DIAF 12, FEst 11, GOT A 11, GOT B 12 and malate dehydrogenase MDH C 22 (Fig. 3).

Private genotypes were present in each group of trees. The early-flowering tree group contained the private heterozygous genotype NDH 26, with 7.7\% frequency. Six private genotypes, DIAF 14 (13\% frequency), GOT B 23 (8.7\% frequency), and DIAF 22, GOT C 14, phosphoglucomutase (PGM) 22 and PGM 33 (each with $4.4 \%$ frequency) were found in the intermediate-flowering tree group. In the late-flowering tree group, two private genotypes were detected, GOT B 33 and PGM 23, with $4.8 \%$ frequency each (Fig. 3).

\section{Genetic variability}

The genetic variabilities in the three phenological groups of clones differed for the individual loci ( $\mathrm{Ta}-$ ble 2). A decreasing trend for $H_{\mathrm{O}}$ was observed for loci 6 PGD and GOT B from the early- to late-flowering tree groups. Excess homozygosity in the latter group was also found in loci NDH and ShDH A. An increase in heterozygosity was observed for loci FEst and ShDH B from the early- to late-flowering tree groups. In addition, excess heterozygotes were observed at locus $\mathrm{MDH} \mathrm{C}$ in the late-flowering tree group. The mean $H_{\mathrm{O}}$ and $P_{\mathrm{g}}$ for the 13 loci did not differ significantly (Table 2 ). Wright's inbreeding coefficient $F$ indicated a slight excess of heterozygotes
Table 2. Genetic variability in three phenological groups of Scots pine plus trees based on isozyme analysis ( 1 - early-flowering, 2 - intermediate-flowering, 3 - late-flowering, $H_{\mathrm{E}}$ - expected heterozygosity, $H_{\mathrm{O}}$ - observed heterozygosity, $F$ - inbreeding coefficient, $P_{\mathrm{g}}$ - genotype polymorphism coefficient)

\begin{tabular}{|c|c|c|c|c|c|}
\hline Locus & Phenological group & $H_{\mathrm{E}}$ & $H_{\mathrm{O}}$ & $F$ & $P_{\mathrm{g}}$ \\
\hline \multirow[t]{3}{*}{$6 \mathrm{PGD}$} & 1 & 0.370 & 0.462 & -0.248 & 0.56 \\
\hline & 2 & 0.446 & 0.522 & -0.169 & 0.61 \\
\hline & 3 & 0.346 & 0.333 & 0.036 & 0.53 \\
\hline \multirow[t]{3}{*}{ DIAF } & 1 & 0.204 & 0.231 & -0.130 & 0.36 \\
\hline & 2 & 0.360 & 0.348 & 0.034 & 0.56 \\
\hline & 3 & 0.091 & 0.095 & -0.050 & 0.17 \\
\hline \multirow[t]{3}{*}{ FEst } & 1 & 0.379 & 0.385 & -0.016 & 0.56 \\
\hline & 2 & 0.436 & 0.478 & -0.098 & 0.60 \\
\hline & 3 & 0.454 & 0.619 & -0.365 & 0.58 \\
\hline \multirow[t]{3}{*}{$\mathrm{GDH}$} & 1 & 0.453 & 0.538 & -0.190 & 0.56 \\
\hline & 2 & 0.499 & 0.435 & 0.129 & 0.65 \\
\hline & 3 & 0.482 & 0.524 & -0.087 & 0.59 \\
\hline \multirow[t]{3}{*}{ GOT A } & 1 & 0.488 & 0.231 & 0.527 & 0.64 \\
\hline & 2 & 0.521 & 0.391 & 0.249 & 0.69 \\
\hline & 3 & 0.475 & 0.286 & 0.399 & 0.63 \\
\hline \multirow[t]{3}{*}{ GOT B } & 1 & 0.530 & 0.615 & -0.162 & 0.63 \\
\hline & 2 & 0.464 & 0.478 & -0.031 & 0.61 \\
\hline & 3 & 0.550 & 0.333 & 0.394 & 0.71 \\
\hline \multirow[t]{3}{*}{ GOT C } & 1 & 0.426 & 0.615 & -0.444 & 0.47 \\
\hline & 2 & 0.417 & 0.391 & 0.061 & 0.60 \\
\hline & 3 & 0.472 & 0.571 & -0.212 & 0.55 \\
\hline \multirow[t]{3}{*}{ MDH A } & 1 & 0.074 & 0.077 & -0.040 & 0.14 \\
\hline & 2 & 0.083 & 0.087 & -0.045 & 0.16 \\
\hline & 3 & 0.046 & 0.048 & -0.024 & 0.09 \\
\hline \multirow[t]{3}{*}{ MDH C } & 1 & 0.497 & 0.462 & 0.071 & 0.64 \\
\hline & 2 & 0.340 & 0.261 & 0.233 & 0.50 \\
\hline & 3 & 0.363 & 0.476 & -0.313 & 0.50 \\
\hline \multirow[t]{3}{*}{$\mathrm{NDH}$} & 1 & 0.411 & 0.385 & 0.065 & 0.60 \\
\hline & 2 & 0.454 & 0.435 & 0.042 & 0.60 \\
\hline & 3 & 0.459 & 0.333 & 0.274 & 0.63 \\
\hline \multirow[t]{3}{*}{ PGM } & 1 & 0.210 & 0.231 & -0.099 & 0.38 \\
\hline & 2 & 0.234 & 0.087 & 0.629 & 0.31 \\
\hline & 3 & 0.177 & 0.143 & 0.192 & 0.26 \\
\hline \multirow[t]{3}{*}{ ShDH A } & 1 & 0.210 & 0.231 & -0.099 & 0.38 \\
\hline & 2 & 0.232 & 0.174 & 0.249 & 0.37 \\
\hline & 3 & 0.543 & 0.476 & 0.123 & 0.73 \\
\hline \multirow[t]{3}{*}{ ShDH B } & 1 & 0.074 & 0.077 & -0.040 & 0.14 \\
\hline & 2 & 0.083 & 0.087 & -0.045 & 0.16 \\
\hline & 3 & 0.210 & 0.238 & -0.135 & 0.36 \\
\hline \multirow[t]{3}{*}{ Mean } & 1 & 0.333 & 0.349 & -0.049 & 0.47 \\
\hline & 2 & 0.351 & 0.321 & 0.086 & 0.49 \\
\hline & 3 & 0.359 & 0.344 & 0.041 & 0.49 \\
\hline
\end{tabular}

in the early-flowering tree group and an excess of homozygotes in the other groups. However, the average observed differences for all of the loci were not statistically significant.

The mean values of genetic differentiation $\left(G_{\mathrm{ST}}\right)$ were low and ranged from 0.016 for the early- and intermediate-flowering tree groups to 0.021 for the early- and late-flowering groups. The value of $G_{\mathrm{ST}}$ 
Table 3. Nei's genetic distance coefficients among three phenological groups of Scots pine plus trees for locus $\mathrm{ShDH}$ $A$ and the mean for 13 isoenzyme loci. 1 - early-flowering, 2 - intermediate-flowering, 3 - late-flowering

\begin{tabular}{cccc}
\hline Phenological group & 1 & 2 & 3 \\
\hline 1 & - & $0.007^{1}$ & $0.142^{1}$ \\
2 & $0.018^{2}$ & - & $0.099^{1}$ \\
3 & $0.024^{2}$ & $0.022^{2}$ & - \\
\hline
\end{tabular}

${ }^{1}$ For locus ShDH A

${ }^{2}$ The mean of 13 loci

between the intermediate- and late-flowering tree groups was statistically significant $\left(G_{\mathrm{ST}}=0.019, \chi^{2}\right.$ $=38.81, \mathrm{P}<0.05)$ and was influenced by the $G_{\mathrm{ST}}$ for loci DIAF $\left(G_{\mathrm{ST}}=0.045, \chi^{2}=7.97, \mathrm{P}<0.05\right)$ and ShDH A $\left(G_{\mathrm{ST}}=0.0906, \chi^{2}=23.92, \mathrm{P}<0.001\right)$. The differences in the values of $G_{\mathrm{ST}}$ for the locus $\mathrm{ShDH}$ A between the early- and late-flowering tree groups $\left(G_{\mathrm{ST}}=0.104, \chi^{2}=21.25, \mathrm{P}<0.001\right)$ and for the locus MDH C between the early- and intermediate-flowering tree groups $\left(G_{\mathrm{ST}}=0.065, \chi^{2}=6.67, \mathrm{P}<0.05\right)$ were also statistically significant.

A comparison of the mean Nei's genetic distances $\left(D_{\mathrm{N}}\right)$ for the 13 loci showed that the three phenological groups were similar to each other. However, the $D_{\mathrm{N}}$ for the locus ShDH A indicated a larger genetic distance between the late-flowering group and the other groups (Table 3 ).

The Ewens-Watterson test for neutrality showed that one of the studied isoenzymatic loci was non-neutral (ShDH A in the late-flowering group) and the other three were close to non-neutrality: $\mathrm{MDH} A$ and ShDH B in the early-flowering group, $\mathrm{GDH}$ in the intermediate-flowering group and $\mathrm{MDH}$ A in the late-flowering group (Table 4). In contrast to the distributions of alleles for loci ShDH A and GDH, which were more even than expected from neutrality,
Table 4. Output of the Ewens-Watterson test for neutrality for isoenzymatic loci that were found to be non-neutral or close to non-neutrality in three phenological groups of Scots pine plus trees. 1 - early-flowering, 2 - intermediate-flowering, 3 - late-flowering; $\mathrm{N}$ - the number of plus trees in a group; $\mathrm{n}$ - the number of alleles

\begin{tabular}{ccccc}
\hline Phenological group $(\mathrm{N})$ & Locus & $\mathrm{n}$ & Observed $F$ & $\pm 95 \% \mathrm{CL}$ \\
\hline $1(26)$ & MDH A & 2 & 0.926 & $0.503-0.926$ \\
& ShDH B & 2 & 0.926 & $0.503-0.926$ \\
$2(46)$ & GDH & 2 & 0.500 & $0.500-0.957$ \\
$3(42)$ & MDH A & 2 & 0.952 & $0.504-0.953$ \\
& ShDH A & 4 & 0.250 & $0.295-0.822$ \\
\hline
\end{tabular}

the distribution of alleles for loci MDH A and ShDH $\mathrm{B}$ were more uneven (Fig. 2), i.e. the frequencies of the most common alleles were higher than expected.

\section{Chloroplast DNA}

The numbers of alleles at five microsatellite chloroplast DNA loci were 19 for the early-flowering tree group and 20 for each of the other two groups. The mean number of alleles per locus was 3.8, 4.0 and 4.0 for the early-, intermediate- and late-flowering tree groups, respectively. An increasing trend in the frequency of alleles CP3 106, CP4 130 and CP7 140 was observed from the early- to late-flowering tree groups (Fig. 4). In contrast, the frequency of alleles CP4 129, CP5 145 and CP7 139 decreased. The frequencies of the other alleles did not show any directional trends.

No significant difference in the frequencies of the individual alleles was observed between the phenological groups of trees. Five private alleles were detected in the intermediate-flowering group (CP4 128, CP4 133, CP6 155, CP7 138 and CP7 144), and two private alleles were present in the late-flowering

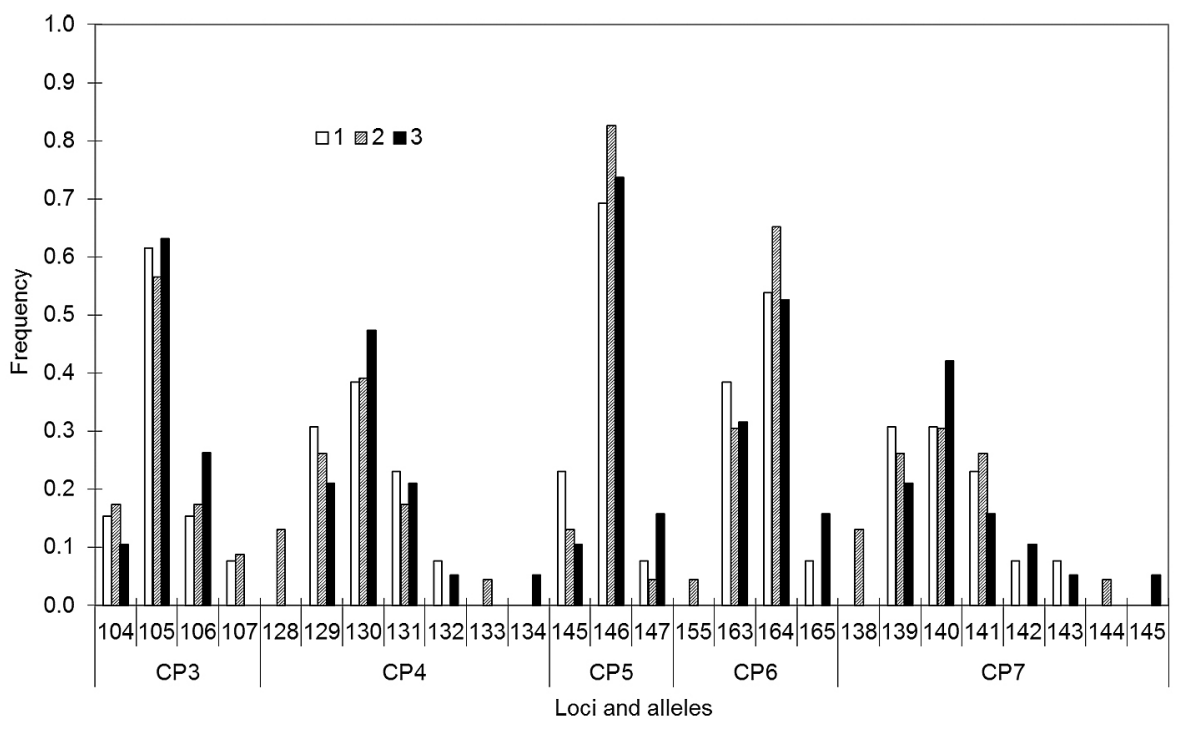

Fig. 4. Frequency and number of chloroplast microsatellite alleles per locus in three phenological groups of Scots pine plus trees (1 - early-flowering, 2 - intermediate-flowering, 3 - late-flowering) 
Table 5. Nei's genetic distance coefficients among three phenological groups of Scots pine plus trees for five chloroplast and three nuclear microsatellite loci. 1 - early-flowering, 2 - intermediate-flowering, 3 - late-flowering

\begin{tabular}{cccc}
\hline Phenological group & 1 & 2 & 3 \\
\hline 1 & - & $0.030^{1}$ & $0.027^{1}$ \\
2 & $0.076^{2}$ & - & $0.046^{1}$ \\
3 & $0.071^{2}$ & $0.060^{2}$ & - \\
\hline
\end{tabular}

${ }^{1}$ The mean of five chloroplast loci

${ }^{2}$ The mean of three nuclear loci

group (CP4 134 and CP7 145). The frequency of the two latter alleles exceeded $5 \%$.

The average haploid genetic diversity $(h)$ decreased from 0.61 in the early-flowering trees to 0.58 and to 0.50 in the intermediate- and late-flowering trees, respectively.

The $D_{\mathrm{N}}$ values indicated that the intermediate- and late-flowering groups were the most genetically distant, whereas the early-flowering group was genetically similar to both of the other groups (Table 5).

\section{Nuclear DNA}

The number of alleles at the three microsatellite nuclear loci was 30,36 and 35 in the early-, intermediate- and late-flowering groups, respectively. The highest number was observed for locus 7.14 (Fig. 5).

The mean number of alleles per locus in the early, intermediate- and late-flowering tree groups was $10.0,12.0$ and 11.7, respectively. Markedly increasing trends in allelic frequency were observed for alleles 204 and 216 at locus 4001 and for alleles 185 and 205 at locus 7.14 from the early- to late-flowering group. A decrease in frequency was observed for al-
Table 6. Genetic parameters of three phenological groups of Scots pine plus trees based on an analysis of nuclear microsatellite loci. 1 - early-flowering, 2 - intermediate-flowering, 3 - late-flowering, $H_{\mathrm{E}}$ - expected heterozygosity, $H_{\mathrm{O}}$ - observed heterozygosity, $F$ - inbreeding coefficient

\begin{tabular}{ccccr}
\hline Locus & Phenological group & $H_{\mathrm{O}}$ & $H_{\mathrm{E}}$ & \multicolumn{1}{c}{$F$} \\
\hline 4001 & 1 & 0.615 & 0.740 & 0.168 \\
& 2 & 0.773 & 0.733 & -0.054 \\
& 3 & 0.714 & 0.762 & 0.062 \\
4011 & 1 & 0.308 & 0.725 & 0.576 \\
& 2 & 0.409 & 0.599 & 0.317 \\
7.14 & 3 & 0.476 & 0.675 & 0.294 \\
& 1 & 0.923 & 0.923 & 0.000 \\
\multirow{4}{*}{ Mean } & 2 & 0.864 & 0.937 & 0.078 \\
& 3 & 0.619 & 0.923 & 0.329 \\
& 1 & 0.615 & 0.796 & 0.248 \\
& 2 & 0.682 & 0.765 & 0.114 \\
& 3 & 0.603 & 0.787 & 0.228 \\
\hline
\end{tabular}

leles 200, 214, 222 at locus 4001 and for alleles 207, 209 and 219 at locus 7.14 (Fig. 5).

In all groups, private alleles were found in two of the three analyzed loci (4001 and 7.14). In the early-flowering tree group, two alleles were private, 208, at locus 4001, and 227, at locus 7.14 (Fig. 5). In the intermediate-flowering tree group, six alleles were private: two at locus 4001 (alleles 202 and 224) and four at locus 7.14 (alleles 221, 229, 237 and 239). Six private alleles were detected for the late-flowering tree group: three at locus 4001 (alleles 198, 226 and 228) and three others at locus 7.14 (alleles 179, 187 and 225). The frequency of each private allele did not exceed $5 \%$.

The $H_{\mathrm{O}}$ differed slightly for particular loci in the analyzed groups of clones. The highest average $H_{\mathrm{O}}$ (0.682) was in the intermediate-flowering group, whereas the lowest average $H_{\mathrm{O}}(0.603)$ was observed

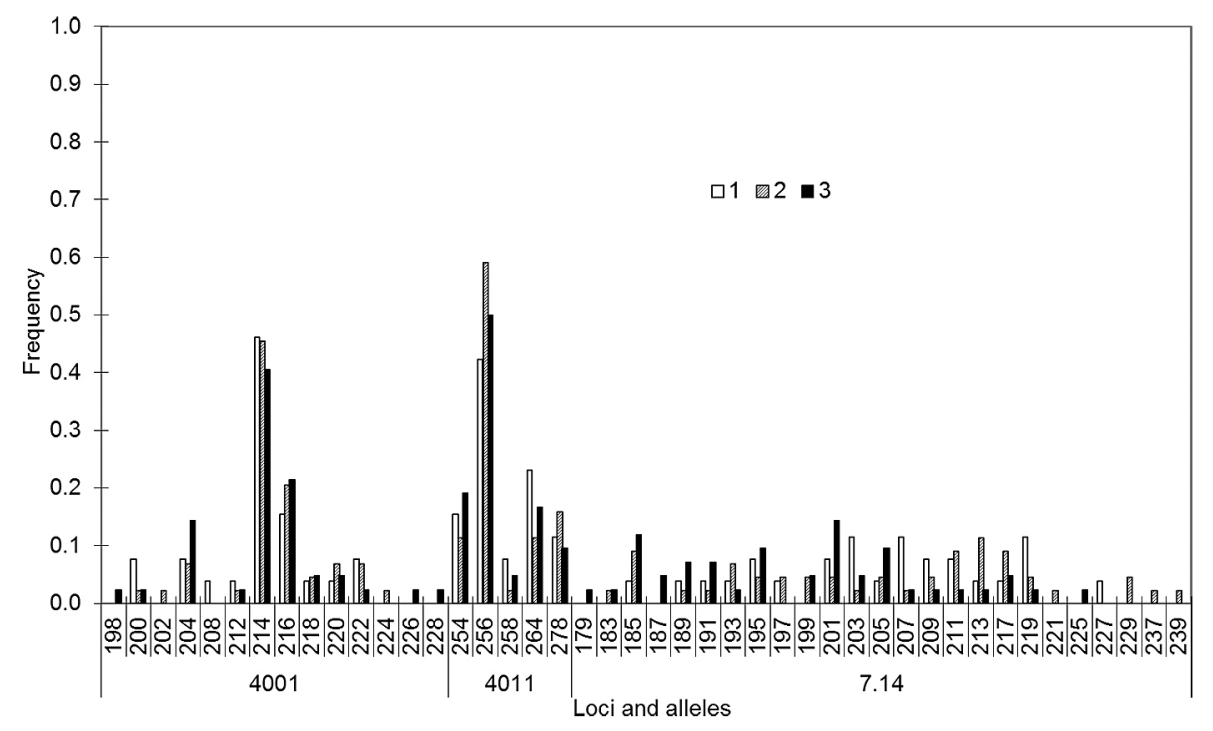

Fig. 5. Frequency of alleles for three nuclear loci in three phenological groups of Scots pine plus trees ( 1 - early-flowering, 2 - intermediate-flowering, 3 - late-flowering) 
in the late-flowering group (Table 6). All three of the groups were characterized by an excess of homozygotes (coefficient $F$ ) in relation to the expected values under Hardy-Weinberg equilibrium.

The value of Nei's genetic distance indicated the similarity of the intermediate- and late-flowering tree groups, whereas the early-flowering group was genetically distant from the other groups (Table 5).

\section{Discussion and conclusions}

This study showed considerable variability in flowering phenology among Scots pine plus trees (from a single forest complex) represented by their clones growing under identical environmental conditions in a seed orchard. The earliest-flowering trees exceeded the latest-flowering trees by more than 12 days.

Identifying differences in the genetic structure or in specific molecular markers associated with flowering time is extremely important from a practical point of view. Clonal seed orchards are often sources of breeding material for trees with useful phenotypic traits. A substantial difference in flowering phenology might lead to limited mating between clones that are not preferred for breeding. Thus, flowering phenology may have a strong effect on the genetic structure and quality of progeny (Gömöry et al. 2003; Wasielewska et al. 2005; Neimane et al. 2009; Ivanek et al. 2013).

The isozyme analysis demonstrated that the intermediate- and late-flowering tree groups are more differentiated in terms of both the number of alleles (2.69 A/L and 2.61 A/L, respectively) and the number of genotypes $(3.46 \mathrm{G} / \mathrm{L}$ and $3.31 \mathrm{G} / \mathrm{L}$, respectively) per locus compared with the early-flowering tree group $(2.46 \mathrm{~A} / \mathrm{L}$ and $2.92 \mathrm{G} / \mathrm{L})$. A statistically significant difference in the allelic frequency was observed for allele ShDH A2 at shikimate dehydrogenase locus A between the late-flowering group and both the early- and intermediate-flowering groups. A similar difference was observed between the late- and intermediate-flowering tree groups in the frequencies of the genotype ShDH A11 at the same locus, suggesting that locus ShDH A may be used as an isoenzymatic marker to identify groups of Scots pine trees differing in flowering time. The function of shikimate dehydrogenase in plant metabolism is related to aromatic amino acid biosynthesis. The $\mathrm{ShDH}$ gene activities have been noted during plant growth and development processes and have been correlated with plant responses to biotic stress (Hermann and Weaver 1999; Fucile et al. 2008), thus it may play an important role in plant flowering phenology.

The mean genetic differentiation $\left(G_{\mathrm{ST}}\right)$ of 13 isozyme loci was low (0.018), indicating that most of the genetic diversity (98.2\%) existed within the groups of clones and that only $1.8 \%$ occurred between these groups. The genetic differentiation was slightly lower than in the Scots pine populations from Germany (2\%) (Müller-Starck 1987) and from northeastern Europe (2.5\%) (Prus-Głowacki et al. 2012). However, the statistically significant differences in the $G_{\mathrm{ST}}$ found between the intermediate- and late-flowering tree groups may be explained by the significant differences in the $G_{\mathrm{ST}}$ for loci ShDH A and DIAF. Moreover, we observed that the late-flowering tree group was the most genetically distant among the three groups primarily because of the significant differences in the $G_{\mathrm{ST}}$ at locus ShDH A between the early- and late-flowering tree groups and between the intermediate- and late-flowering tree groups. Izoenzymatic study of Chung (1981 b) on genetic structure of the early- and late-flowering pines did not show significant differences in frequencies of allozymes between flowering groups. Our study generally confirmed Chung's results, except for ShDH locus (not used by Chung), which was significantly differentiated among the flowering groups. The recent analyses of 51 European populations of P. sylvestris showed a significant genetic differentiation at $\mathrm{ShDH}$ $\mathrm{A}$ and ShDH B loci across Europe (Prus-Głowacki et al. 2012). Mean values of observed heterozygosity $\mathrm{(Ho}$ ) for locus ShDH A in the Iberian Peninsula and Scotland were 0.421 and 0.590 , respectively, whereas in Central and Eastern Europe they were 0.273 and 0.287 , respectively. Mean values of $\mathrm{Ho}$ for locus ShDH B were 0.181 and 0.140 , respectively, in the former two localities, and 0.162 and 0.138 , respectively, in the latter ones. The values for Central and Eastern Europe were close to those we found in the studied seed orchard. Such genetic differences at a large geographic scale could have consequences in adaptation processes and in flowering phenology. The results of the neutrality test also suggest that non-neutral ShDH A locus may be considered as an indicator of flowering time.

Both chloroplast and nuclear microsatellite markers did not show significant differences in the genetic structure or allelic frequencies of the analyzed phenological groups. Additionally, the chloroplast markers did not differentiate neither male nor female flowering groups in a Scots pine seed orchard in Latvia (Neimane et al. 2009). The current state of knowledge is that SSRs have no function (except for being putatively related with recombination processes); however they can be subject to hitch-hicking (Nielsen et al. 2006; Casa et al. 2005; Lazrek et al. 2009; Neimane et al. 2009). None of the microsatellite markers that were analyzed in this study can be used as indicators of flowering time in Scots pine.

Private and rare alleles that occurred exclusively in one of the three studied phenological groups of trees were observed in several isozyme and DNA loci. 
However, these alleles cannot be used as markers of flowering phenology due to their low frequencies in the studied phenological groups.

Our results suggest that only some isozyme markers among tested, particularly those that are related to shikimate dehydrogenase loci, are associated with the phenological development of Scots pine and, specifically, with flowering time. These isoenzymatic markers could be used when planning and establishing seed orchards to obtain synchronized pollination of certain clones which is important for seed production of a desirable quality. However, further more detailed study is needed to confirm this result.

\section{Acknowledgments}

We wish to thank Prof. Andrzej Kolk for his help in the field and two anonymous reviewers for helpful comments.

\section{Funding}

This study was part of a project that received financial support from the General Directorate of State Forests in Poland.

\section{References}

Auckland L., Bui T., Zhou Y., Shepherd M., Williams C. 2002. Conifer microsatellite handbook. College Station, Texas A\&M University, Texas.

Boes T.K., Brandle J.R., Lovett W.R. 1991. Characterization of flowering phenology and seed yield in a Pinus sylvestris clonal seed orchard in Nebraska. Canadian Journal of Forest Research 21: 17211729.

Burczyk J., Chalupka W. 1997. Flowering and cone production variability and its effect on parental balance in Scots pine clonal seed orchard. Annals of Forest Science 54: 129-144.

Casa A.M., Mitchell S.E., Hamblin M.T., Sun H., Bowers J.E., Paterson A.H., Aquadro C.F., Kresovich S. 2005. Diversity and selection in sorghum: Simultaneous analyses using simple sequence repeats. Theoretical and Applied Genetics 111: 23-30.

Chung M.S. 1981a. Flowering characteristics of Pinus sylvestris with special emphasis on the reproductive adaptation to local temperature factor. Acta Forestalia Fennica 169: 1-69.

Chung M.S. 1981b. Biochemical methods for determining population structure in Pinus sylvestris $\mathrm{L}$. Acta Forestalia Fennica 173: 1-28.

Doyle J.J., Doyle J.L. 1990. Isolation of plant DNA from fresh tissue. Focus 12: 13-15.
Fucile G., Falconer S., Christendat D. 2008. Evolutionary diversification of plant shikimate kinase gene duplication. PloS Genetics 4: e1000292

Gömöry D., Bruchánik R., Longauer R. 2003. Fertility variation and flowering asynchrony in Pinus sylvestris: consequences for the genetic structure of progeny in seed orchard. Forest Ecology and Management 174: 117-126.

Hedrick P.W. 2011. Genetics of populations. Jones \& Bartlett Publishers, pp. 316-324.

Hermann K.M., Weaver L.M. 1999. The shikimate pathway. Annual Review of Plant Physiology and Plant Molecular Biology 50: 473-503.

Ivanek O., Procházková Z., Matějka K. 2013. Analysis of the genetic structure of a model Scots pine (Pinus sylvestris) seed orchard for development of management strategies. Journal of Forest Science 59: 377-385.

Jonsson A., Ekberg I., Eriksson G. 1976. Flowering in a seed orchard of Pinus sylvestris L. Studia Forestalia Suecica 135: 1-38.

Karhu A., Hurme P., Karjalainen M., Karvonen P., Kärkkäinen K., Neale D., Savolainen O. 1996. Do molecular markers reflect patterns of differentiation in adaptive traits of conifers? Theoretical and Applied Genetics 93: 215-221.

Lazrek F., Roussel V., Ronfort J., Cardinet G., Chardon F., Aouani M.E., Huguet T. 2009. The use of neutral and non-neutral SSRs to analyse the genetic structure of a Tunisian collection of Medicago truncatula lines and to reveal associations with eco-environmental variables. Genetica 135: 391-402.

Muona O., Szmidt A. 1985. A multilocus study of natural populations of Pinus sylvestris. In: Population Genetics in Forestry. Gregorius H.R. (ed.). Springer-Verlag, New York, pp. 226-240.

Müller-Starck G. 1987. Genetic differentiation among seed samples from provenances of Pinus sylvestris L. Silvae Genetica 36: 232-238.

Nei M. 1972. Genetic distance between populations. American Naturalist 106: 283-292.

Nei M. 1978. Estimation of average heterozygosity and genetic distance from a small number of individuals. Genetics 89: 583-590.

Neimane U., Baumanis I., Veinberga I., Škipars V., Rungíis D. 2009. Genetic aspects of phenological distinctions in Scots pine populations. Mežzinātne 19: 49-63.

Nielsen E.E., Hansen M.M., Meldrup D. 2006. Evidence of microsatellite hitch-hiking selection in Atlantic cod (Gadus morhua L.): implications for inferring population structure in nonmodel organisms. Molecular Ecology 15: 3219-3229.

Peakall R., Smouse P.E. 2006 GENALEX 6: genetic analysis in Excel. Population genetic software for 
teaching and research. Molecular Ecology Notes 6: 288-295.

Peakall R., Smouse P.E. 2012. GenAlEx 6.5: genetic analysis in Excel. Population genetic software for teaching and research-an update. Bioinformatics 28: 2537-2539.

Provan J., Soranzo N., Wilson N.J., Goldstein D.B., Powell W. 1999. A low mutation rate for chloroplast microsatellites. Genetics 153: 943-947.

Prus-Głowacki W., Stephan B.R. 1994. Genetic variation of Pinus sylvestris from Spain in relation to other European populations. Silvae Genetica 43: $7-14$.

Prus-Głowacki W., Urbaniak L., Bujas E., Curtu A. 2012. Genetic variation of isolated and peripheral populations of Pinus sylvestris (L.) from glacial refugia. Flora 207: $150-158$.

Puglisi S., Lovreglio R., Attolico M. 1999. Subpopulation differentiation along elevational transects within two Italian populations of Scots pine (Pinus sylvestris L.). Forest Genetics 6: 247-256.

Sarvas R. 1962. Investigations on the flowering and seed crop of Pinus sylvestris. Communicationes Instituti Forestalis Fenniae 53: 1-198.

Soranzo N., Provan J., Powell W. 1998. Characterization of microsatellite loci in Pinus sylvestris L. Molecular Ecology 7: 1260-1261.

Vendramin G.G., Lelli L., Rossi P., Morgante M. 1996. A set of primers for the amplification of 20 chloroplast microsatellites in Pinaceae. Molecular Ecology 5: 595-598.

Wasielewska M., Klemm M., Burczyk J. 2005. Genetic diversity and mating system of Scots pine plus trees. Dendrobiology 53: 57-62.

Yeh F.C., Yang R.C., Boyle T. 1999. POPGENE version 1.31. Microsoft Window-based Freeware for Population Genetic Analysis, University of Alberta. Edmonton, Canada. 